УДК 621.365.3+ 621.3.036.61+ 519.876.5

\title{
МАТЕМАТИЧЕСКОЕ МОДЕЛИРОВАНИЕ РАБОТЫ БИМЕТАЛЛИЧЕСКИХ ПОДОВЫХ ЭЛЕКТРОДОВ ДУГОВЫХ СТАЛЕПЛАВИЛЬНЫХ ПЕЧЕЙ ПОСТОЯННОГО ТОКА
}

\author{
Мужиченко А.Ф., Полещук М.А., канд. техн. наук, Шевцов А.В. \\ Институт электросварки им. Е.О. Патона НАН Украины, ул. Боженко 11, г. Киев, 03150, Украина
}

Створено комп'ютерну модель температурних полів, котрі виникають у водоохлоджуваних біметалевих подових електродах при роботі дугових сталеплавильних печей постійного струму. Модель розкриває різні конструкції подових електродів, способи з'єднання їх мідної та сталевої частин і дозволяє вибрати оптимальну конструкцію подового електроду для конкретних умов виплавлення металу.

Библ. 14, рис. 5.
Создана компьютерная модель температурных полей возникающих в водоохлаждаемых биметаллических подовых электродах при работе дуговых сталеплавильных печей постоянного тока. Модель рассматривает различные конструкции подовых электродов, способы соединения их медной и стальной части и позволяет выбрать оптимальную конструкцию подового электрода для конкретных условий выплавки металла.
The computer model of temperature fields that emerge in water-cooled bimetallic hearth-level electrodes during the operation of arc steel-making furnaces of direct current was created. The model considers different structures of bimetallic hearth-level electrodes, the methods to connect their cooper and steel parts, and allows to choose optimum structure of hearth-level electrode for the specific conditions of metal smelting.

Ключевые слова: дуговые сталеплавильные печи, постоянный ток, биметаллические подовые электроды, математическое моделирование, температурные поля, оптимальная конструкция.

$\mathrm{F} 1=\mathrm{F} 1(x, y, z, t)-$ плотность тепловых источни-

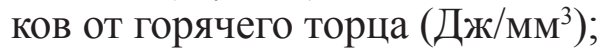

$\rho$ - плотность металла в различных частях кг $/ \mathrm{Mм}^{3}$; $\lambda$ - коэффициент теплопроводности; Вт/(мм $\left.{ }^{\circ} \mathrm{C}\right)$;

$x, y, z$ - координаты мм;

$\sigma$ - удельные электропроводности стали и меди, а также их зоны соединения, $\mathrm{OM}^{-1} \mathrm{MM}^{-1}$;

$q$ - объёмная плотность источников теплоты $\left(\right.$ Дж/Mм $\left.{ }^{3}\right)$;

$\mathrm{F} 2=\mathrm{F} 2(x, y, z, t)-$ плотность джоулевых источников; (Дж/ $\left.\mathrm{MM}^{3}\right)$;

Мировое производство стали уже превысило 1,6 миллиарда тонн. Порядка одной трети этого количества выплавляют в печах, работающих как на переменном ДСП, так и на постоянном токе ДСП ПТ. Сейчас в мире имеется около 1000 ДСП и 200 ДСП ПТ [1].

В настоящее время ДСП ПТ находят все более широкое применение в промышленности. Так около 70 \% вновь внедряемых в производство агрегатов составляют печи постоянного тока [2]. Это связанно с тем, что ДСП ПТ по сравнению с $c_{\mathrm{v}}$ - удельная теплоёмкость Дж/(кг $\left.{ }^{0} \mathrm{C}\right)$;

$\mathrm{t}$ - время, сек;

$\mathrm{T}=\mathrm{T}(x, y, z, t)-$ температура, ${ }^{0} \mathrm{C}$;

$\varphi$ - потенциал электрического поля, В.

\section{Сокращения:}

ДСП - дуговых сталеплавильная печь;

ДСП ПТ - дуговых сталеплавильная печь постоянного тока.

ДСП имеют более низкие расходы электроэнергии, огнеупоров и графитированых электродов. Кроме того, работа ДСП ПТ характеризуется пониженным уровнем шума и меньшими выбросами пыли и газов, что улучшает условия труда [3].

Обычно ДСП ПТ (рис. 1) включает: стальной корпус (1), свод (2), футеровку (3). В центре свода располагается графитированный электродкатод (4). В днище корпуса расположен анод (5) (один или несколько). Катод и анод соединены с источником питания постоянного тока (6). Тепло- 
та в плавильном пространстве ДСП ПТ выделяется при горении электрической дуги (7) между торцом катода и расплавляемым металлом (8).

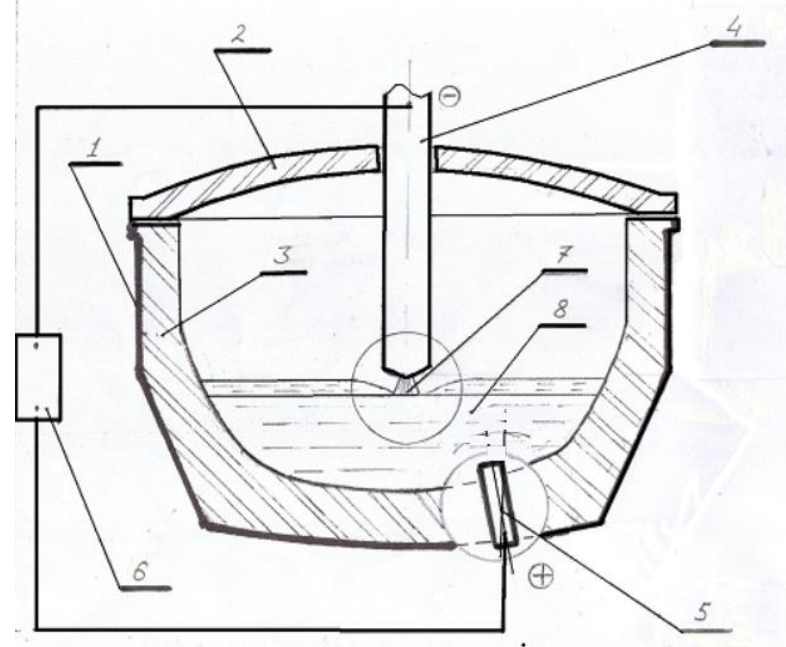

Рис. 1. Схема ДСП ПТ. Наименования позиций 1-8 приведень в тексте.

Подовый электрод-анод, служит для подвода электрического тока через подину (огнеупорную футеровку) к расплавляемому металлу и работает в очень жестких условиях больших токовых и тепловых нагрузок. К этим нагрузкам иногда добавляется агрессивное воздействие металлического расплава, например, при выплавке феросплавов.

Подовый электрод должен обладать высокой эксплуатационной надежностью; хорошей электро- и теплопроводностью, чтобы обеспечить требуемые технологические параметры выплавки металла, минимальное количество ремонтов печи, ее высокую производительность и малые электрические потери.

В настоящее время в ДСП ПТ наиболее часто применяются подовые электроды стержневого типа. Они изготавливаются водоохлаждаемыми биметаллическими (сталь-медь) [4]. Стальной торец этих электродов контактирует с металлическим расплавом в плавильном пространстве. Медная часть электродов, охлаждаемая водой, находится ниже подины.

В ДСП ПТ используют различные конструкции биметаллических подовых электродов стержневого типа. Они отличаются размерами, формой наружной поверхности, токоподводом, системой водяного охлаждения, а также способом соединения медных и стальных частей. При работе ДСП ПТ тепловое состояние подового электрода может определяться конструкцией его стальной части. Возможны два принципиально различных варианта ее исполнения. В первом стальная часть выполняется сплошного сечения, а во втором, она имеет форму стакана с толстым дном, одетого на медный стержень (рис. 2). При хорошем электрическом и тепловом контактах меди со сталью медный стержень внутри стального может существенным образом увеличить теплоотвод от торца электрода, обращенного в плавильное пространство, и тем самым снизить его рабочую температуру.

В электродах первого исполнения соединение медной и стальной частей осуществляется, как правило, различными видами сварки или пайки. В электродах второго исполнения медный стержень может быть соединен со сталью не только сваркой или пайкой, но и различными механическими способами, например резьбовым или шлицевым соединением $[5,6,7]$.

Температурное поле подового электрода, возникающее в процессе работы ДСП ПТ, является одним из наиболее важных критериев, определяющих его стойкость, а значит и работоспособность всей печи. Оно зависит от конструкции подового электрода, интенсивности его охлаждения и режимов плавки. С целью определения наиболее оптимальной конструкции биметаллического подового электрода мы провели компьютерное моделирование их температурных полей. Стойкость подовых электродов различной конструкции оценивалась нами по температуре их стальных торцов, обращённых в плавильное пространство.

Распределение теплоты в электроде описывается известным уравнением теплопроводности с учетом джоулевых источников теплоты:

$$
\frac{\partial}{\partial t}\left(\alpha_{v} T\right)=\frac{\partial}{\partial t}\left(\lambda \frac{\partial T}{\partial x}\right)+\frac{\partial}{\partial t}\left(\lambda \frac{\partial T}{\partial y}\right)+\frac{\partial}{\partial t}\left(\lambda \frac{\partial T}{\partial z}\right)+F_{1}+F_{2} .
$$

Плотности джоулевых источников определяются путём решения электрической задачи.

Для расчёта плотностей токов в биметаллическом стержне нами используется модель электрических процессов, сформулированная в виде 
поля потенциалов [8]:

$\operatorname{div}(S \operatorname{grad} j)=0$.

По результатам расчётов плотностей токов определяем объемную плотность джоулевых источников теплоты, выделяемой в электроде:

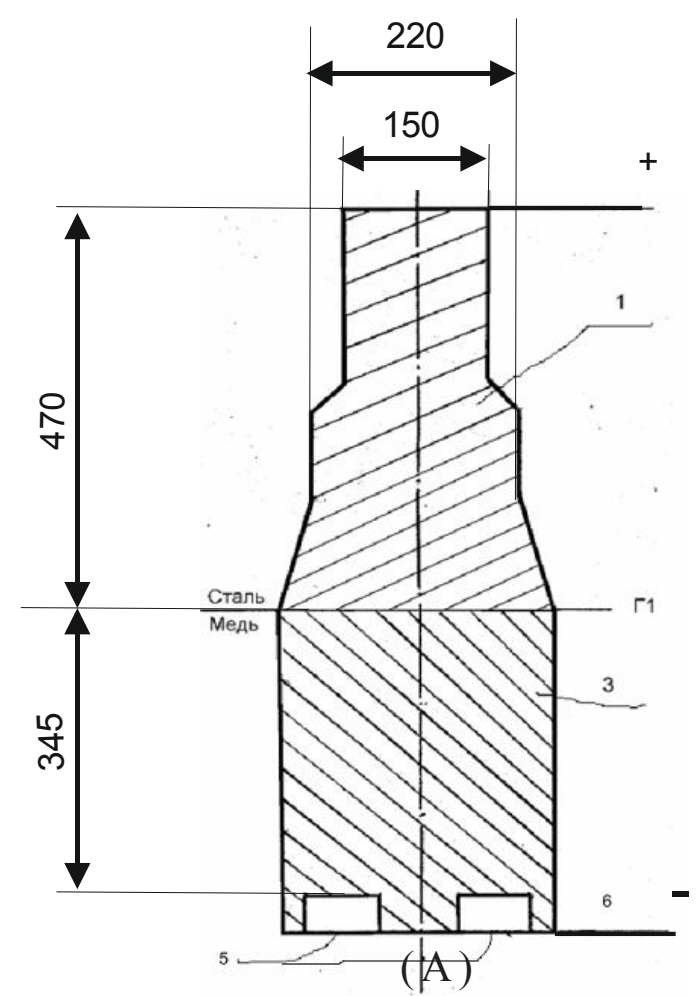

$$
q=\sigma|\operatorname{grad} \varphi|^{2}
$$

Величины $\rho, C_{v}, \lambda$ и $\sigma-$ в уравнениях (1), (2), (3) зависят от температуры.

При моделировании электрических и температурных полей подовых электродов, задавались следующие граничные условия:

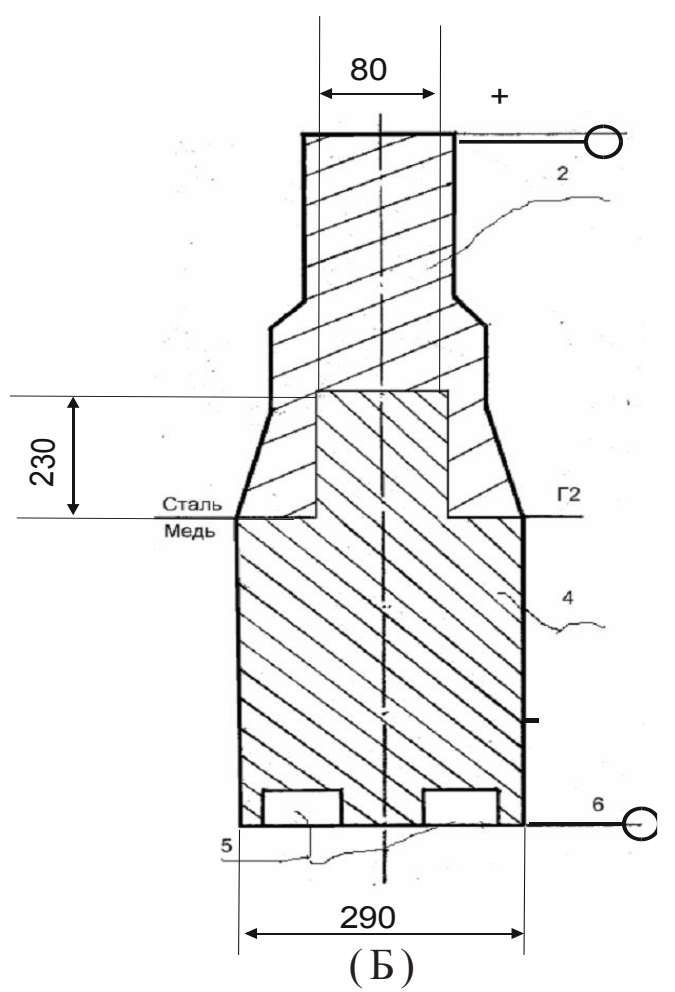

Рис. 2. Эскизы подовых электродов, использованных при моделировании температурных полей, возникающих в процессе работы ДСП ПТ.

А-исполнение 1, Б-исполнение 2.

1 - стальная часть сплочного сечения; 2 -стальная часть в форме стакана; 3 -медная часть; 4 -медная часть со стержнем; 5 - система водоохлаждения; 6 - токоподвод, Г1 и Г2 - границы раздела медь-сталь.

- боковые поверхности подовых электродов считались электрически и теплоизолированными;

- на стальном торце электрода, обращенном в плавильное пространство печи, задавались коэффициент теплопередачи и температура расплавленного металла;

- на охлаждаемой поверхности медной части электрода задавались коэффициент теплопередачи, зависящий от температуры медной стенки, и температура воды;

- на границе раздела между материалами электродов Г1 (первое исполнение) и Г2 (второе исполнение) имеются дополнительные электрическое и тепловое сопротивления, величина которых определяется способом соединения меди со сталью;

- между холодными и горячими торцами электродов задавалось значение рабочего постоянного тока.

Моделирование электрических и температурных полей подовых электродов проведено применительно к работе 12-тонной ДСП ПТ, при плавке отсевов ферросплавов. Эта печь имеет два подовых электрода. Выплавка проводилась при следующих технологических режимах: напряжение источника питания $150 \mathrm{~B}$; полный рабочий 
ток 17 кА (ток на каждом подовом электроде 8,5 кА); средняя температура расплава $1300{ }^{\circ} \mathrm{C}$; температура охлаждающей воды $40{ }^{\circ} \mathrm{C}$.

Адекватность модели реальному процессу выплавки оценивалась по показаниям тепмопар, стационарно установленых в медной части.

Моделировалась работа электродов двух конструктивных исполнений, размеры которых приведены на рис. 2. В нижней части электрода соответствующие поля строились только на участке медной части, расположенной между границей раздела сталь-медь и водоохлаждаемой поверхностью. Определялось также влияние способа соединения медных и стальных частей на температурные поля подовых электродов.

Известно, что коэффициент теплопередачи между нагретой жидкостью и ограничивающей ее твердой поверхностью зависит от скорости их относительного перемещения. Применительно к водяному охлаждению этот коэффициент определяется по общепринятым соотношениям [9]. При температуре теплоотдающей поверхности до $100{ }^{\circ} \mathrm{C}$ он нами принят равным $1200 \mathrm{BT} / \mathrm{M}^{2}$, a при температуре поверхности $100{ }^{\circ} \mathrm{C}$ (после начала поверхностного кипения) принят равным 6000 Вт/м². Коэффициент теплопередачи от расплавленного металла к стальному торцу подового электрода был принят равным 814 Вт/м². Значение этого коэффициента экспериментально определенно при исследовании теплообмена между металлической ванной и водоохлаждаемым кристаллизатором в процессе электрошлакового переплава [10].

Рассмотрены два способа соединения меди со сталью в подовом электроде: первый, при котором создается металлическая связь между медью и сталью (различные способы сварки плавлением и пайки) и второй,-- путем механического соединения.

Биметаллический подовый электрод, полученный сваркой плавлением или пайкой, следует рассматривать состоящим из трех зон: стальную и медную с соответствующими коэффициентами удельного электрического и теплового сопротивления, и переходную, в которой величины этих коэффициентов изменяются. Поэтому для практических расчетов в переходной зоне можно принять их среднее значение. Таким об- разом, электрическое и тепловое сопротивление всей переходной зоны зависит только от ее ширины. Как показано в [11], при различных способах сварки ширина этой зоны не превышает 16 мм. Поскольку протяженность переходной зоны по сравнению с размерами медной и стальной частей подового электрода совершенно незначительна, то при моделировании дополнительными сопротивлениями в этой зоне можно пренебречь.

В то же время, при механическом способе соединения стального корпуса с медной частью (исполнение 2) на границе Г2 имеют место контактное электрическое и термическое сопротивления. Как установлено в [12], на границе раздела меди с углеродистой сталью при различных тепловых потоках скачок температуры может находиться в пределах от 60 до $150{ }^{\circ} \mathrm{C}$. Такому скачку температур соответствует контактный коэффициент теплопередачи $50 \mathrm{BT} /\left(\mathrm{M}^{2.0} \mathrm{C}\right)$ [13].

Удельная электрическая проводимость в этом контакте была нами принята равной $5 * 10^{5} \mathrm{CM} / \mathrm{M}^{2}$ [14].

Анализ температурных полей подового электрода первого исполнения, приведенных на рис. 3, a, показывает, что температура торца стального электрода с учётом джоулевых источников теплоты (левая сторона) достигает $1090{ }^{\circ} \mathrm{C}$, а без учёта (правая сторона) $1083{ }^{\circ} \mathrm{C}$. Таким образом относительная разница температур в этом случае не превышает $1 \%$. Слабое влияние джоулевых источников теплоты на температуру торца подового электрода объясняется низкой плотностью тока, проходящего через электрод; хорошей электропроводностью материала электрода и идеальным контактом между медью и сталью. Поэтому величина тока, проходящего через подовый электрод, мало влияет на его температурное поле, которое в основном определяется тепловым потоком от плавильного пространства.

Для подтверждения этого вывода мы построили модель температурного поля подового электрода при прохождении через него постоянного тока величиной 40 кА, т.е. примерно в пять раз выше, чем в модели, приведенной на рис. 3 , $a$, сохранив неизменными остальные технологические параметры и геометрические размеры. При этом разница температур стального торца с уче- 
том и без учета выделения джоулевых источников теплоты не превысила $40{ }^{\circ} \mathrm{C}$. Следовательно, при моделировании температурных полей подо-

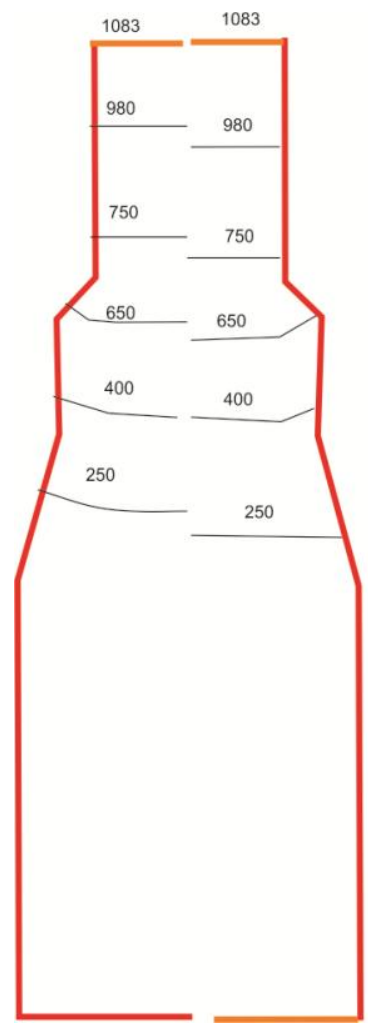

(A) вых электродов, возникающих при выплавке различных марок сталей, можно не учитывать изменение величины рабочего тока.

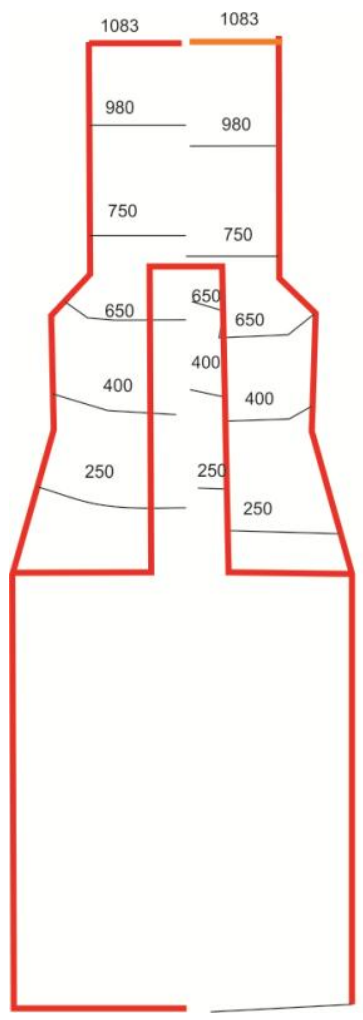

(Б)

Рис. 3. Температурные поля ( $\left.{ }^{\circ} \mathrm{C}\right)$ подовых электродов:

А - исполнение 1 при идеальном контакте (сварка плавлением меди со сталью).

Б-исполнение 2 при различных типах контактов.

Режимы плавки в ДСП ПТ и граничные условия указаны в тексте. Геометрические размеры электродов приведены на рис 2.

Сравнение температурных полей подовых электродов, в исполнении 2, при идеальном и плохом контактах (рис. 3, б) показывает, что качество контакта, а значит и способ соединения разнородных металлов, значительно влияет на температуру стального торца электрода, обращенного в плавильное пространство. Так при плохом контакте (рис 3, б, правая сторона) эта температура на $1800{ }^{\circ} \mathrm{C}$ выше, чем при идеальном (рис 3, б, левая сторона).

Сравнение температурных полей подовых электродов различных исполнений (рис. 3, $a$ и 6 , левые стороны) показывает, что наличие медного стержня внутри стальной части при идеальном контакте снижает температуру стального торца на $45^{\circ} \mathrm{C}$. В тоже время при плохом контакте медного стержня со сталью температура стального торца примерно на $120{ }^{\circ} \mathrm{C}$ выше, чем у электрода в исполнении 1. Таким образом, механическое соединение меди со сталью в подовом электроде (исполнение 2) не только нивелирует наличие медного стержня, но и резко повышает температуру торца подового электрода $\mathrm{T}_{\text {т }}$.

Анализ температурных кривых подовых электродов в исполнении 2, приведенных на рис. 4, показывает, что при идеальном контакте меди со сталью существенное снижение температуры торца подового электрода, обращенного в пла- 
вильное пространство, наблюдается, если длина и диаметр медного стержня превышают 60 \% длины и диаметра стальной части электрода.

Длина медного стержня в электроде исполнения 2 230мм, диаметр 80мм.

Для выплавки конкретных марок сталей или ферросплавов в плавильном пространстве ДСП ПТ необходимо иметь соответствующую температуру. При этом, чем выше температура плавле- ния металла тем больше должна быть величина тока, проходящего через подовый электрод. Ранее было установлено, что величина рабочего тока в процессе плавки слабо влияет на температурное поле подового электрода. Этот вывод позволяет моделировать температурные поля подовых электродов при переплаве различных марок сталей, используя при моделировании одну и ту же величину рабочего тока.

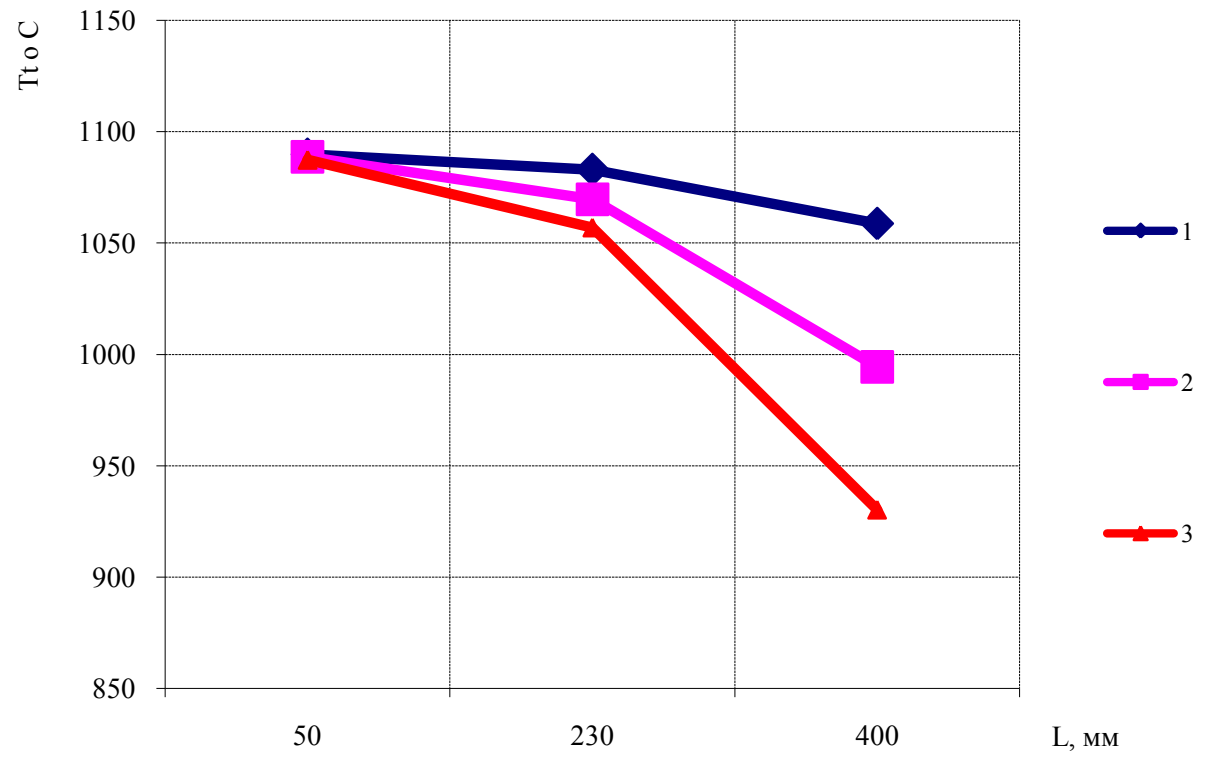

Рис. 4. Зависимости температуры стального торца подового электрода $\left(T_{m}\right)$ в исполнении 2 от длины медного стержня (L) при разных его диаметрах (D). $1-D=40$ мм, $2-D=80$ мм, $3-D=120$ мм. Режимы плавок указаны в тексте.

Анализ кривых, показанных на рис. 5, построенных при величине тока в подовом электроде 8,5 кА, свидетельствует, что при температуре расплава в плавильном пространстве ДСП ПТ свыше $1600{ }^{\circ} \mathrm{C}$, стальной торец электрода может расплавиться. Вероятность расплавления стального торца электрода тем выше, чем хуже контакт между его медной и стальной частями.

Оценивая приведенные выше результаты, можно сделать следующие выводы:

- разработанная модель позволяет рассматривать температурные поля подовых электродов различных конструкций, способов соединения медной и стальной частей и выбрать оптимальную конструкцию подового электрода;

- установлено, что величина постоянного тока, проходящего через подовый электрод, в пределах необходимых для выплавки различных сталей и ферросплавов, слабо влияет на температурное поле электрода;

- показано, что температура торца электрода, обращенного в плавильное пространство, существенным образом зависит от способа соединения меди со сталью. Наиболее низкая температура наблюдается при соединении разнородных металлов сваркой плавлением или пайкой;

- наличие медного стержня внутри стальной части электрода оказывает заметное влияние на температуру стального торца электрода если его длина и диаметр больше чем 60 \% соответствующих размеров стальной части. 


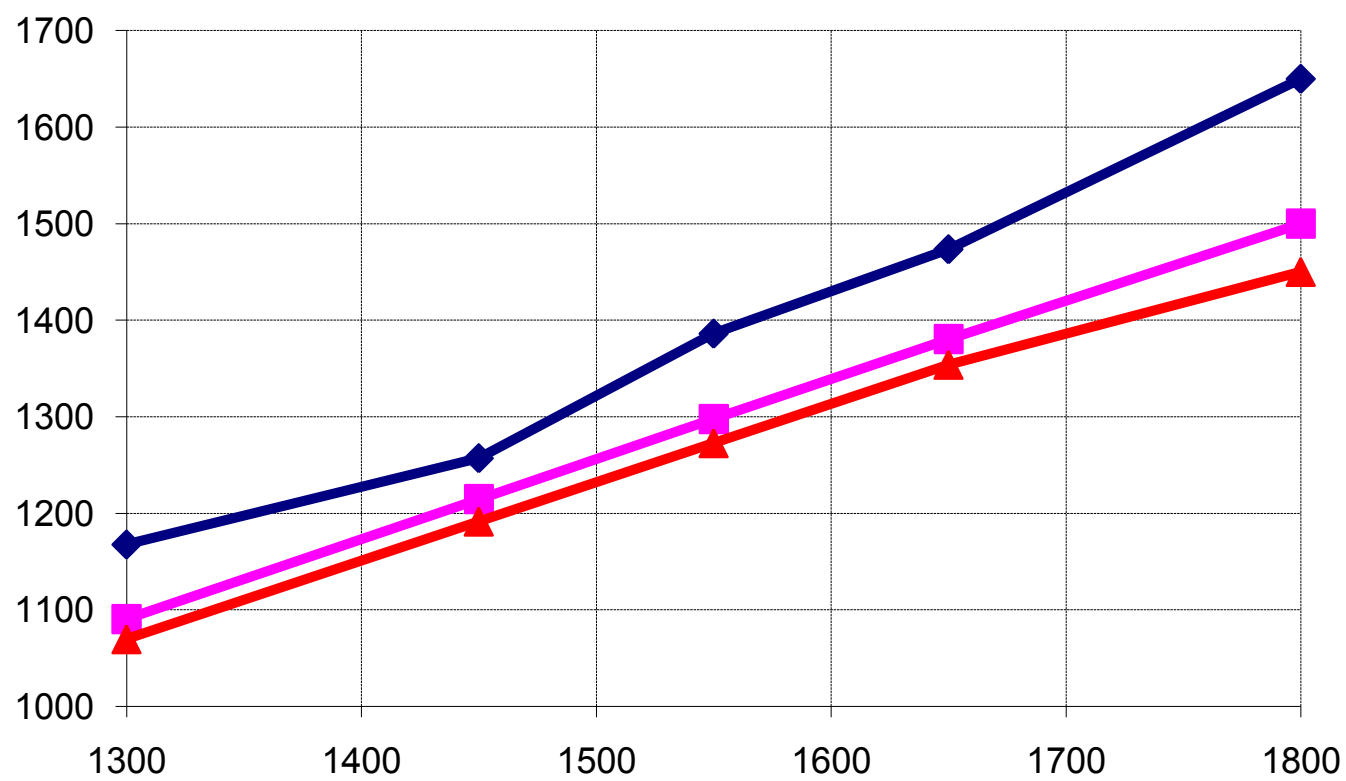

Рис. 5. Зависимости температуры стального торца подового электрода $\left(T_{m},{ }^{\circ} \mathrm{C}\right)$ от температуры расплавленного металла $\left(T_{p}{ }^{\circ} \mathrm{C}\right)$ в плавильном пространстве ДСП ПТ. 1 - подовый электрод исполнения 2, плохой контакт; 2 - подовый электрод исполнения 1, идеальный контакт; 3 - подовый электрод исполнения 2, идеальный контакт.

\section{ЛИТЕРАТУРА}

1. «Steeltime» - информационный. портал о черной и цветной металлургии, май 2013 г.

2. Дюдкин Д.А,, Кисиленко В.В. Производство стали, том 1, «Теплотехник», Москва, 2008

3. Малиновский В.С. Ярных Л.В. Дуговые печи постоянного тока нового поколения -новый путь эффективной реконструкции металлургического машиностроения России « Металлургия машиностроения» - 2001г.- №1.- С. 12-19.

4. Каплун М.Я. Подовые електроды дуговых печей постоянного тока «Электрометаллургия»-2008-№9. - С.21-25

5. Патент США №4101725 кл.13-18 1979

6. Патент Украины № 88236 С2 МПК H05B7/00

7. Патент РФ № 2022480 МПК Н05В7/08 опубликовано 30.10.1994

8. Eric R.N. Slag properties and design issues pertiment to matte smelting electric furnaces // VVII Intern/ conf. On molten slags fluxes and salts (Cape Town January, 25-28, 2004 ). - Cape Town - P531-
541 (The South African Institute of Mining and Metallurgy, 2004/

9. Х. Уонг. Основные формулы и данные по теплообмену для инженеров - Москва «Атомиздат» 1979.- $216 \mathrm{c}$.

10..Тепловые процессы при электрошлаковом переплаве/ Б.И. Медовар. В.Л. Шевцов. Г.С. Маринский и др. -Киев «Наукова думка» 1978.-304c

11. Сварное соединение меди со сталью в подовом электроде дуговой сталеплавильной печи постоянного тока, «Электрометаллургия» №4, 2013г., Москва, с. 7-9.

12. Шлыков Ю.П. Ганин Е.А. Царевский С.Н. Контактное термическое сопротивление.-Москва «Энергия» 1977.- 328c.

13. Heat Transfer Division (November 1970). "Conduction in Solids - Steady State, Imperfect Metal-to-Metal Surface Contact". General Electric Inc.

14. Kenneth L. Kaiser. (2004). Electromagnetic Compatibility Handbook. CRC Press. pp. 13-52. ISBN 978-0-8493-2087-3. 


\section{MATHEMATICAL MODELING OF OPERATION OF BIMETALLIC HEARTH- LEVEL ELECTRODES OF ARC STEEL- MAKING FURNACES OF DIRECT CURRENT}

\author{
Muzhichenko A.F. ${ }^{1}$, Atroshenko M.G. ${ }^{1}$, \\ Bogachenko A.G. ${ }^{1}$, Poleschuk M.A. ${ }^{1}$, \\ Shevtsov A.V. ${ }^{1}$, Fridman M.A. ${ }^{2}$
}

${ }^{1}$ E. O. Paton Electric Welding Institute of National Academy of Sciences of Ukraine, 11 Bojenko st. , Kiev, 03150, Ukraine

${ }^{2}$ PrJSC "Ferrotreiding",59 Ujnoe Shosse, Zaporojie, 03150, Ukraine

The computer model of temperature fields appearing in water-cooled bimetallic hearth-level electrodes during operation of arc steel-making furnaces of direct current was developed. This model considers the influence of heat flow from furnace melting area and Joule heat sources, appearing in it, on the steel end of the hearth-level electrode. The model examines different structures of hearthlevel electrodes, methods of joining their cooper and steel parts and allows to choose optimal structure of hearth-level electrode for the specific conditions of metal smelting. It is shown that the temperature of the electrode end, directed into melting area, significantly depends on method of joining its cooper and steel parts. Presence of the cooper core inside the electrode steel part, significantly effects temperature of the electrode steel end only if its length and diameter are larger than $60 \%$ of corresponding size of the steel part.

\section{References 14, figures 5.}

Key words: arc steel-making furnaces, direct current, bimetallic hearth-level electrodes, mathematic modelling, temperature fields, optimum structure.

1. «Steeltime» informational portal about ferrous and non-ferrous metallurgy, May 2013. (Rus.)

2. Diydkin D..A,, Kisilenko. V.V .Steel production, Volume 1, "Teplotekhnik", Moskow, 2008. (Rus.)

3. Malinovskii V.S., Iarnuh L.V. New generation arc furnaces of direct current - a new way of effective reconstruction of metallurgical machinery in Russia “Metalurgia mashinostoenia” 2001.- №1.- p. 12-19. (Rus.)

4. Kaplun M. I. Hearth-level electrodes of arc furnaces of direct current. "Electrometalurgia" 2008-№9.- p.21-25 (Rus.)

5. USA Patent №4101725 кл.13-18 1979 (Eng.)

6. Ukraine Patent № 88236 C2 МПК H05B7/00 (Ukr.)

7. Russian Federation Patent № 2022480 МПК H05B7/08 published 30.10.1994 (Rus.)

8. Eric R.N. Slag properties and design issues pertiment to matte smelting electric furnaces // VVII Intern/ conf. On molten slags fluxes and salts (Cape Town January, 25-28, 2004 ). - Cape Town - P531541 (The South African Institute of Mining and Metallurgy, 2004/(Eng)

9. H Yong Basic formulas and data on heat transfer for engineers. - Moskow "Atomizdat" 1979. (Rus.)

10. Thermal processesduring electroslag remelting /B.I. Medovar. V.L. Shevtsov, G.S. Marinskii and others. - Kiev "Naukova Dumka" 1978 - 304 p. (Rus.)

11. Bogachenko A.G., Lakomskii V.I., Mishenko D.D. and others. Welded connection of copper and steel in hearth-level electrode of arc furnace of direct current, "Electrometalurgia" №4, 2013, Moskow, p. 7-9. (Rus.)

12. Shlykov I. P., Ganin I.A. Tsarevskii S.N. Contact thermal resistance. - Moskow "Energia" 1977.-328p. with illustrations.

13. Heat Transfer Division (November 1970). "Conduction in Solids - Steady State, Imperfect Metal-to-Metal Surface Contact". General Electric Inc.

14. Kenneth L. Kaiser. (2004). Electromagnetic Compatibility Handbook. CRC Press. pp. 13-52. ISBN 978-0-8493-2087-3.

Получено 23.07.2014 Received 23.07.2014 